\title{
Effectiveness of Unfractionated Heparin in Normal Saline versus Dextrose for Achieving and Maintaining Therapeutic Anti-Factor Xa Levels in Patients with Non-ST-Elevation Acute Coronary Syndrome
}

\author{
Amanda C Jacques, Colleen Lougheed, Erika MacDonald, Alan Karovitch, and Pierre Giguère
}

\begin{abstract}
Background: : Unfractionated heparin (UFH) administered by IV infusion is effective in preventing myocardial infarction and death after non-ST-elevation acute coronary syndrome. At the authors' centre, preparations of UFH in $0.9 \%$ sodium chloride (normal saline; UFHNS) were used during a shortage of commercially available UFH in dextrose $5 \%$ in water (UFH-D5W), the usual preparation. Anecdotal observations raised concerns about the effectiveness of the saline-based preparation in achieving minimally therapeutic anticoagulation.
\end{abstract}

Objective: To compare the effectiveness of UFH-NS and UFH-D5W for achieving and maintaining therapeutic anti-factor Xa levels in patients with non-ST-elevation acute coronary syndrome.

Methods: A retrospective cohort study was conducted with 2 groups of 100 consecutive patients who received either UFH-NS or UFH-D5W for a minimum of $24 \mathrm{~h}$ after non-ST-elevation acute coronary syndrome in accordance with a weight-based dosing nomogram.

Results: A minimally therapeutic level of anti-Xa ( $\geq 0.31 \mathrm{IU} / \mathrm{mL})$ was achieved within $24 \mathrm{~h}$ for $92 \%$ of the patients receiving UFH-D5W and $67 \%$ of those receiving UFH-NS (absolute risk difference 25\%, 95\% confidence interval [CI] $13.4 \%-36.6 \% ; p<0.001)$. Infusion of UFHNS was associated with lower probability of achieving minimally therapeutic anticoagulation (hazard ratio [HR] 2.30, 95\% CI $1.68-3.15 ; p<0.001)$ and maintaining therapeutic anticoagulation (HR 2.31, 95\% CI 1.69-3.17; $p<0.001)$ relative to UFH-D5W. Significant differences in the numbers of patients with subtherapeutic and therapeutic anticoagulation, favouring UFH-D5W, were observed at each of the first, second, and third anti-Xa measurements $(p<0.05)$. Patients receiving UFH-NS required a greater median number of adjustments to the infusion rate during the first $48 \mathrm{~h}(1.0 \mathrm{v} .0 .5$ adjustment per day, $p<0.001)$. There was no difference between groups in terms of major reductions in hemoglobin.

Conclusions: Infusion of UFH-NS was inferior to UFH-D5W for achieving and maintaining therapeutic anticoagulation in patients with non-ST-elevation acute coronary syndrome. Until further study,

\begin{abstract}
RÉSUMÉ
Contexte : La perfusion intraveineuse d'héparine non fractionnée (HNF) est efficace pour prévenir l'infarctus du myocarde et la mortalité après la survenue d'un syndrome coronarien aigu sans élévation du segment ST. Au centre hospitalier des auteurs, des préparations de ce médicament dans du chlorure de sodium à $0,9 \%$ (solution physiologique salée [SP]; HNF-SP) ont été utilisées lors d'une pénurie de solutions commercialisées d'HNF dans du dextrose à $5 \%$ dans l'eau (HNF-D5E) d'usage habituel. Quelques observations ont soulevé des inquiétudes quant à l'efficacité des préparations à base de SP pour obtenir une anticoagulation thérapeutique minimale.
\end{abstract}

Objectif : Comparer l'efficacité de l'HNF dans la SP et le D5E pour obtenir et maintenir des concentrations thérapeutiques d'anti-facteur Xa chez des patients ayant subi un syndrome coronarien aigu sans élévation du segment ST.

Méthodes : Une étude de cohorte rétrospective a été menée à partir de deux séries consécutives de 100 patients qui ont reçu de l'HNF dans une $\mathrm{SP}$ ou du D5E pendant un minimum de 24 heures après la survenue du syndrome coronarien aigu sans élévation du segment ST, selon un nomogramme posologique en fonction du poids.

Résultats : Des concentrations thérapeutiques minimales d'anti-Xa $(\geq 0,31 \mathrm{UI} / \mathrm{mL})$ ont été obtenues en 24 heures chez $92 \%$ des patients ayant reçu l'HNF-D5E et chez $67 \%$ de ceux ayant reçu l'HNF-SP (différence de risque absolu de $25 \%$, intervalle de confiance [IC] à $95 \%$ de $13,4 \%$ à $36,6 \% ; p<0,001)$. La perfusion de la préparation à base de SP a été associée à une probabilité plus faible d'obtenir une anticoagulation thérapeutique minimale (rapport de risque [RR] de 2,30, IC à $95 \%$ de $1,68$ à 3,$15 ; p<0,001)$ et de maintenir une anticoagulation thérapeutique (RR de 2,31, IC à $95 \%$ de 1,69 à 3,17; $p<0,001)$ par rapport à la préparation dans du D5E. Des différences significatives dans le nombre de patients ayant obtenu une anticoagulation thérapeutique et subthérapeutique, en faveur de l'HNF-D5E, ont été observées à chacune des premières, deuxièmes et troisièmes mesures des concentrations d'anti-Xa $(p<0,05)$. Les patients ayant reçu l'HNF-SP ont requis un nombre médian supérieur d'ajustements de la vitesse de perfusion pendant les 48 premières heures ( 1,0 contre 0,5 ajustement par jour, $p<0,001)$. Il n'y avait aucune différence entre les groupes en termes de réductions importantes de l'hémoglobine.

Conclusions : La perfusion d'HNF-SP s'est révélée inférieure à celle de 
saline-based heparin infusions should be used with caution, and patients should be monitored closely to ensure timely achievement and maintenance of therapeutic anticoagulation.

Keywords: unfractionated heparin, acute coronary syndrome, normal saline, dextrose, anti-Xa
l'HNF-D5E pour obtenir et maintenir une anticoagulation thérapeutique chez les patients ayant subi un syndrome coronarien aigu sans élévation du segment ST. Jusqu'à ce que d'autres études soient menées, la perfusion d'héparine dans une solution physiologique salée doit être utilisée avec circonspection et les patients doivent être surveillés étroitement afin d'assurer l'obtention en temps opportun et le maintien d'une anticoagulation thérapeutique.

Mots clés : héparine non fractionnée, syndrome coronarien aigu, solution physiologique salée, dextrose, anti-Xa

[Traduction par l'éditeur]
$25 \mathrm{~mL}$ of heparin 1000 units/mL to a $250-\mathrm{mL}$ bag of NS with an assigned expiry of 28 days at room temperature.-9 The concentration of the manufactured UFH-NS solution was approximately 83 units $/ \mathrm{mL}$ (due to an average $10 \%$ [25 mL] overfill of the commercial $250-\mathrm{mL}$ bags of NS and $25-\mathrm{mL}$ volume of concentrated heparin solution added). Stability testing of prepared heparin solutions was not available at the centre at the time of this study.

Following the product substitution described above, concerns were raised regarding the effectiveness of UFH-NS in achieving and maintaining therapeutic anticoagulation. Several patients who received UFH-NS were reported to display persistently subtherapeutic anti-factor Xa levels, despite adjustment of the infusion rate according to a weight-based UFH dosing nomogram. Substitution with an extemporaneously prepared solution of UFH-D5W for some of these patients resulted in rapid achievement of therapeutic anti-Xa levels. Similar anecdotal observations were recorded in 2005 when the policy was to use solutions of UFH-NS for patients with diabetes mellitus, in an effort to minimize glucose intake.

The purpose of this study was to compare the effectiveness of UFH-NS and UFH-D5W for achieving and maintaining therapeutic anti-Xa levels. A literature review indicated that the phenomenon observed with UFH-NS had not been previously described and that studies comparing the efficacy and safety of different UFH solutions in vivo had not been conducted.

\section{METHODS}

\section{Heparin Dosing Nomogram}

The ability to accurately titrate doses of UFH, which has been identified as a high-risk medication by international safety organizations, ${ }^{10}$ is imperative in ensuring both efficacy of anticoagulation and patient safety. ${ }^{11}$ A weight-based UFH dosing nomogram for patients presenting with non-STelevation acute coronary syndrome has been used at the authors' centre since 2000.12 A preprinted form (Appendix 1, available online at www.cjhp-online.ca/index.php/cjhp/issue/ view/96/showToc) is used to order an initial UFH bolus and 
infusion rate based on the patient's actual body weight. Infusions are administered and adjusted by nursing staff according to anti-Xa levels, which are measured $6 \mathrm{~h}$ after the initial bolus and initiation of the infusion, and $6 \mathrm{~h}$ after every infusion rate adjustment for subtherapeutic (anti-Xa $\leq 0.30 \mathrm{IU} / \mathrm{mL}$ ) or supratherapeutic (anti-Xa $\geq 0.71 \mathrm{IU} / \mathrm{mL}$ ) results. Once therapeutic anticoagulation is achieved (anti-Xa $0.31-70$ $\mathrm{IU} / \mathrm{mL}$ ), the infusion rate is maintained, and anti-Xa levels are measured daily.

\section{Study Design}

This retrospective cohort study compared the anti-Xa levels of 2 groups of 100 consecutive patients each (total $n=200)$ who received the standard UFH-D5W solution during the months preceding or UFH-NS in the months following the vendor back order of UFH-D5W. The study was approved by the Ottawa Hospital Research Ethics Boards.

\section{Outcomes}

The primary objective of this study was to compare the percentage of patients in each group achieving a minimally therapeutic anti-Xa level within the first $24 \mathrm{~h}$ after initiation of heparin infusion (i.e., any anti-Xa $\geq 0.31 \mathrm{IU} / \mathrm{mL}$ within $24 \mathrm{~h}$ ). Exceeding this threshold was selected as the primary objective because achieving at least minimally therapeutic anticoagulation in a timely manner has been the main concern among health care providers at the study centre. The secondary objectives were comparing the time to achievement of minimally therapeutic anticoagulation (time to first anti-Xa $\geq$ $0.31 \mathrm{IU} / \mathrm{mL}$ ) and the time to maintenance of therapeutic anticoagulation (time to first of two consecutive therapeutic anti$\mathrm{Xa}$ values, i.e., $0.31-0.70 \mathrm{IU} / \mathrm{mL}$ ), as well as the percentages of patients with subtherapeutic (anti-Xa $\leq 0.30 \mathrm{IU} / \mathrm{mL}$ ), therapeutic (anti-Xa 0.31-0.70 IU/mL), and supratherapeutic (anti-Xa $\geq 0.71 \mathrm{IU} / \mathrm{mL}$ ) results at the first, second, and third measurement. Surrogate outcomes for safety and workload assessment (specifically, percentage of patients with a decrease in hemoglobin of at least $20 \mathrm{~g} / \mathrm{L}$ during the UFH infusion or within $24 \mathrm{~h}$ of its discontinuation and median number of daily adjustments in infusion rate during the first $48 \mathrm{~h}$ ) were compared between the groups. If a statistically significant difference was observed for the primary objective, associations with demographic characteristics (age, sex, weight, presence of diabetes, estimated creatinine clearance, and treatment site) were to be explored with multivariate regression analyses.

\section{Patient Selection}

The institution's pharmacy software was used to generate a report of all patients receiving IV infusions of UFH-D5W or UFH-NS at 3 treatment sites within the centre (2 campuses of a tertiary care teaching hospital and a cardiovascular health centre) in the 12 months before and the 12 months after solution substitution, which occurred in December 2009. Patients receiving UFH on the date of solution substitution were excluded to avoid misclassification. One of the investigators assessed patient eligibility by accessing patients' health records consecutively according to starting date and time of the UFH infusion. Patients eligible for inclusion were adults with a confirmed diagnosis of non-ST-elevation acute coronary syndrome who received IV infusions of UFH for a minimum of $24 \mathrm{~h}$ with a minimum of 2 anti-Xa measurements and adherence to the dosing nomogram. Accurate body weight was required for use of the dosing nomogram, and patient weights as recorded on the preprinted heparin order form were considered accurate if they could be confirmed with at least one other information source (i.e., weight as recorded on an echocardiogram, interventional procedure report, or other documentation in the medical record). Patients were excluded if the weight on the heparin order form was inaccurate or could not be verified. Patients were also excluded if they had received UFH dosages not in compliance with the nomogram (e.g., omission of the initial bolus or incorrect infusion rate adjustment). Those with inappropriately timed measurement of the anti-Xa level were also excluded (i.e., if the sample for the first anti-Xa measurement, due at $6 \mathrm{~h}$, was collected more than $1 \mathrm{~h}$ early or late, or if the sample for any subsequent anti-Xa measurement was collected more than $2 \mathrm{~h}$ early or $4 \mathrm{~h}$ late). Daily anti-Xa levels were considered to be due at 0600 but were accepted if samples were collected up to $2 \mathrm{~h}$ early or $4 \mathrm{~h}$ late. After mandatory measurement of anti-Xa at $6 \mathrm{~h}$ after infusion initiation, the timing of further anti-Xa measurements for each patient was dependent on the result of the previous measurement, in accordance with the nomogram. For patients receiving UFH-NS, physician orders were reviewed to confirm that the UFH solution had not been changed and prepared in D5W during the course of therapy.

\section{Sample Size}

This study was powered for the primary objective of comparing the percentage of patients in each group achieving the minimally therapeutic anti-Xa level within $24 \mathrm{~h}$ after initiation of the UFH infusion. The required sample size was estimated according to a 2-sided level of significance $\alpha=0.05$ and power of 0.80 . A validation study of the earlier version of the weight-based nomogram used at the study centre showed that $24 \mathrm{~h}$ after initiation of a UFH-D5W infusion, $94.7 \%$ of patients had an anti-Xa level greater than $0.35 \mathrm{IU} / \mathrm{mL}$ (the minimally therapeutic anti-Xa threshold as defined for purposes of the validation study). ${ }^{12}$ Therefore, inclusion of 200 patients (100 in each cohort) would allow detection of an absolute difference of $13 \%$ or more between the groups. 


\section{Statistical Analyses}

The data were analyzed with SPSS statistical software (version 13.0; SPSS Inc., Chicago, Illinois) with a level of significance set at $\alpha=0.05$. Categorical data were analyzed with the $\chi^{2}$ test. Time-to-event outcomes were compared using Kaplan-Meier curves. Multivariate analyses with solution type and demographic characteristics were performed using Cox proportional hazards. Continuous variables were compared with the 2-tailed Student $t$ test if the data were normally distributed or the Mann-Whitney $U$ test if not normally distributed.

\section{RESULTS}

To collect data for 200 patients meeting the inclusion criteria (100 in each group), a total of 2623 patient charts were reviewed, over treatment periods of about 11 months for the UFH-D5W group and 9 months for the UFH-NS group (see Figure 1). The most common reason for exclusion was use of UFH for an indication other than confirmed non-ST-elevation acute coronary syndrome, in 1656 (63.1\%) of the patients. Examples of other indications were ST-segment elevation myocardial infarction and venous thromboembolism, for which the centre has separate UFH dosing protocols, and unconfirmed non-ST-elevation acute coronary syndrome. Nonadherence to the UFH dosing nomogram (i.e., initial bolus omitted, incorrect or unverified patient weight, incorrect anti-Xa sampling time, or incorrect dosage adjustment) led to the exclusion of another 569 (21.7\%) of the patients. The characteristics of patients included in the analysis were similar between the groups (Table 1). The median duration of infusion and interquartile range (IQR) were similar between patients receiving UFH-D5W and UFH-NS: $62.9 \mathrm{~h}$ (IQR 46.1-84.6 h) versus $55.8 \mathrm{~h}$ (IQR 41.2-75.0 h).

\section{Primary Outcome}

Within the first $24 \mathrm{~h}$, a minimally therapeutic anti-Xa level had been achieved for $92 \%$ of the patients receiving UFHD5W but only $67 \%$ of those receiving UFH-NS (absolute risk difference $25 \%, 95 \%$ confidence interval [CI] $13.4 \%-36.6 \%$; $p<0.001)$.

\section{Secondary Outcomes}

\section{Achievement and Maintenance of Therapeutic Anticoagulation}

The probability of achieving minimally therapeutic anticoagulation over time was significantly lower for patients receiving UFH-NS than for those receiving UFH-D5W (hazard ratio [HR] 2.30, 95\% CI 1.68-3.15; $p<0.001$ ). The probability of maintaining therapeutic anticoagulation over time was similarly lower for patients receiving UFH-NS than for those receiving UFH-D5W (HR 2.31, 95\% CI 1.69-3.17, $p<0.001)$. Kaplan-Meier curves demonstrating the time required to achieve and maintain therapeutic anticoagulation (Figures 2 and 3, respectively) show initial separation between the groups at the time of the first anti-Xa measurement $(6 \mathrm{~h})$; for maintenance of therapeutic anticoagulation, this separation

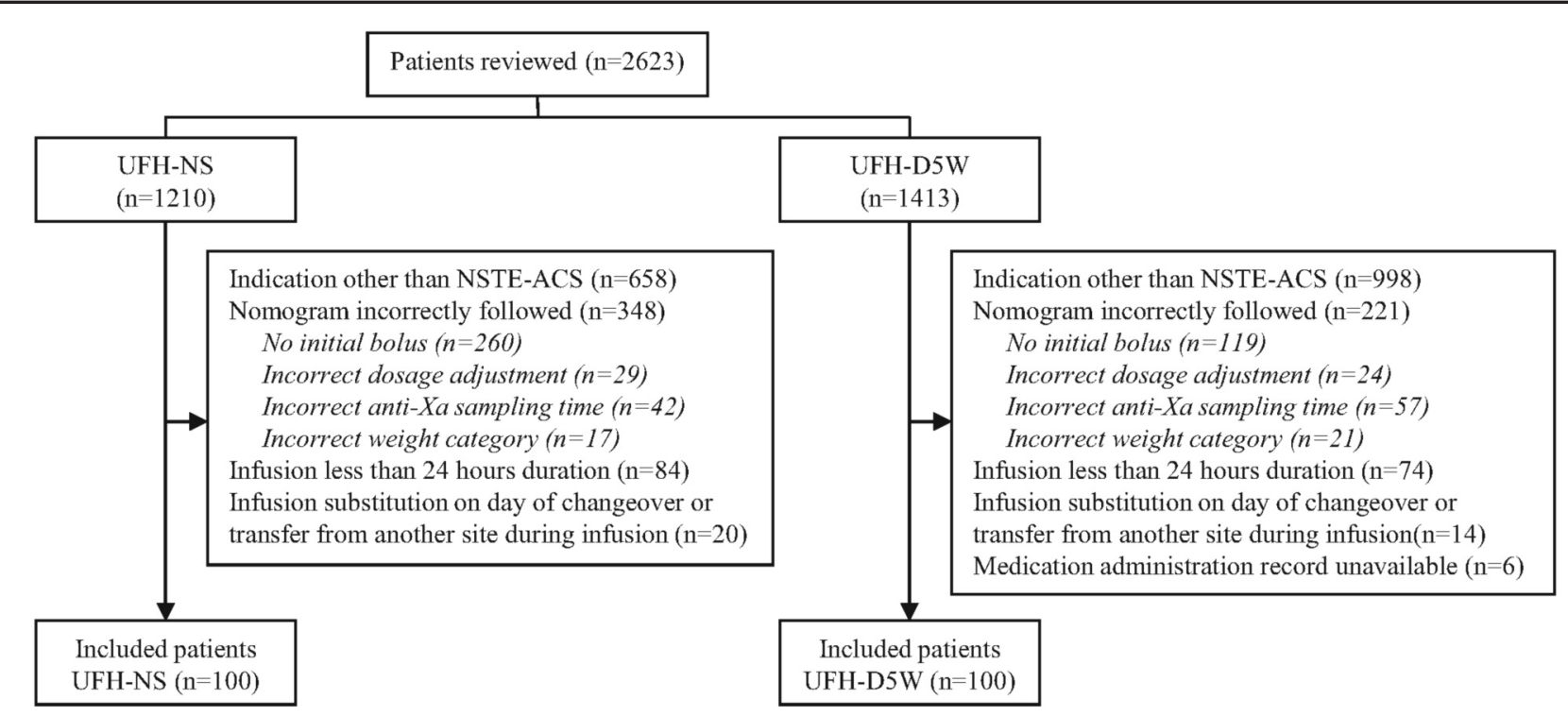

Figure 1. Process for identifying patients with non-ST-elevation acute coronary syndrome (NSTE-ACS) eligible for inclusion in a study comparing unfractionated heparin in normal saline (UFH-NS) and unfractionated heparin in dextrose $5 \%$ in water (UFH-D5W). 
Table 1. Characteristics of Patients with Non-ST-Elevation Acute Coronary Syndromes

\begin{tabular}{|c|c|c|}
\hline \multirow[b]{2}{*}{ Characteristic } & \multicolumn{2}{|c|}{ Study Group; No. of Patients* } \\
\hline & UFH-NS $(n=100)$ & UFH-D5W $(n=100)$ \\
\hline Age (years), mean (SD) & $71 \quad(14)$ & $71(14)$ \\
\hline Sex, male & 69 & 62 \\
\hline \multicolumn{3}{|l|}{ Treatment site } \\
\hline Site 1 & 62 & 53 \\
\hline Site 2 or 3 & 38 & 47 \\
\hline Weight (kg), mean (SD) & $77.9 \quad(19.0)$ & $76.7(18.6)$ \\
\hline$<50$ & 4 & 3 \\
\hline $50-60$ & 14 & 10 \\
\hline $60-70$ & 21 & 22 \\
\hline $70-80$ & 17 & 27 \\
\hline$>80$ & 44 & 38 \\
\hline Diabetes mellitus & 38 & 37 \\
\hline Estimated CrCL (mL/min), mean (SD) & $47 \quad(28)$ & $52 \quad(27)$ \\
\hline$<15 \mathrm{~mL} / \mathrm{min}$ & 10 & 6 \\
\hline \multicolumn{3}{|l|}{ Baseline laboratory values, mean (SD) } \\
\hline $\mathrm{aPTT}(\mathrm{s})$ & $27 \quad(5)$ & $26 \quad(3)$ \\
\hline INR & $1.1 \quad(0.4)$ & $1.1 \quad(0.2)$ \\
\hline Platelets (× 109/L) & $252(100)$ & 264 (109) \\
\hline Hemoglobin (g/L) & $126 \quad(21)$ & $128 \quad(21)$ \\
\hline \multicolumn{3}{|c|}{$\begin{array}{l}\text { aPTT = activated partial thromboplastin time, } \mathrm{CrCL}=\text { creatinine clearance, calculated with } \\
\text { Cockcroft-Gault equation, INR = international normalized ratio, SD = standard deviation, } \\
\text { UFH-D5W = heparin sodium } 100 \text { units } / \mathrm{mL} \text { in dextrose } 5 \% \text { in water, UFH-NS = heparin sodium } \\
100 \text { units } / \mathrm{mL} \text { in } 0.9 \% \text { sodium chloride. } \\
\text { ^Except where indicated otherwise. }\end{array}$} \\
\hline
\end{tabular}

was preserved over the treatment duration (Figure 3). Prespecified multivariate analyses did not reveal any associations between age, sex, weight, creatinine clearance, or treatment site and time required to achieve or maintain therapeutic anticoagulation. The presence of diabetes was associated with a lower probability of maintaining therapeutic anticoagulation (HR 1.38 , 95\% CI 1.01-1.89; $p=0.04)$ but not with the achievement of minimally therapeutic anticoagulation $(p=0.10)$.

\section{Distribution of Anti-Xa Results over Time}

At each of 3 time points (first, second, and third measurements of anti-Xa), a significantly greater number of patients receiving UFH-NS had subtherapeutic anti-Xa results and a significantly lower number of such patients were in the therapeutic anti-Xa range relative to patients receiving UFHD5W (Table 2). Rates of supratherapeutic anti-Xa levels at these time points were similar between the groups.

\section{Surrogate Outcomes for Safety and Workload}

The percentage of patients with a reduction of hemoglobin of at least $20 \mathrm{~g} / \mathrm{L}$ during the infusion or within $24 \mathrm{~h}$ after UFH discontinuation was not significantly different between the UFH-NS and UFH-D5W groups $(10 \%$ versus $14 \% ; p=0.38)$. However, patients receiving UFH-NS required a significantly greater number of adjustments to the infusion rate during the first $48 \mathrm{~h}$ than those receiving UFH-D5W (median 1.0 adjustment [IQR $0.5-2.0$ ] per day versus 0.5 adjustment [IQR 0.0-1.0] per day; $p<0.001)$.

\section{DISCUSSION}

Patients with non-ST-elevation acute coronary syndrome who received UFH-NS had significant impairment of both achievement and maintenance of therapeutic anticoagulation relative to those who received UFH-D5W. More specifically, there was an absolute difference of $25 \%$ fewer patients achieving the minimally therapeutic anticoagulation threshold within $24 \mathrm{~h}$ in the UFH-NS group $(p<0.001)$. At any point over the treatment duration, patients receiving UFH-NS were 2.3 times less likely to achieve or maintain minimally therapeutic anticoagulation ( $p<0.001$ for both). These differences were significantly associated with the solution type but not with demographic or clinical characteristics, with the exception of diabetes. The presence of diabetes was weakly associated with reduced ability to maintain therapeutic anticoagulation, a finding that requires validation with further study.

In terms of safety, it appears that UFH-D5W was not associated with significantly greater over-anticoagulation than UFH-NS, as the groups displayed similar rates of supratherapeutic anti-Xa results over the first 3 measurements. The 

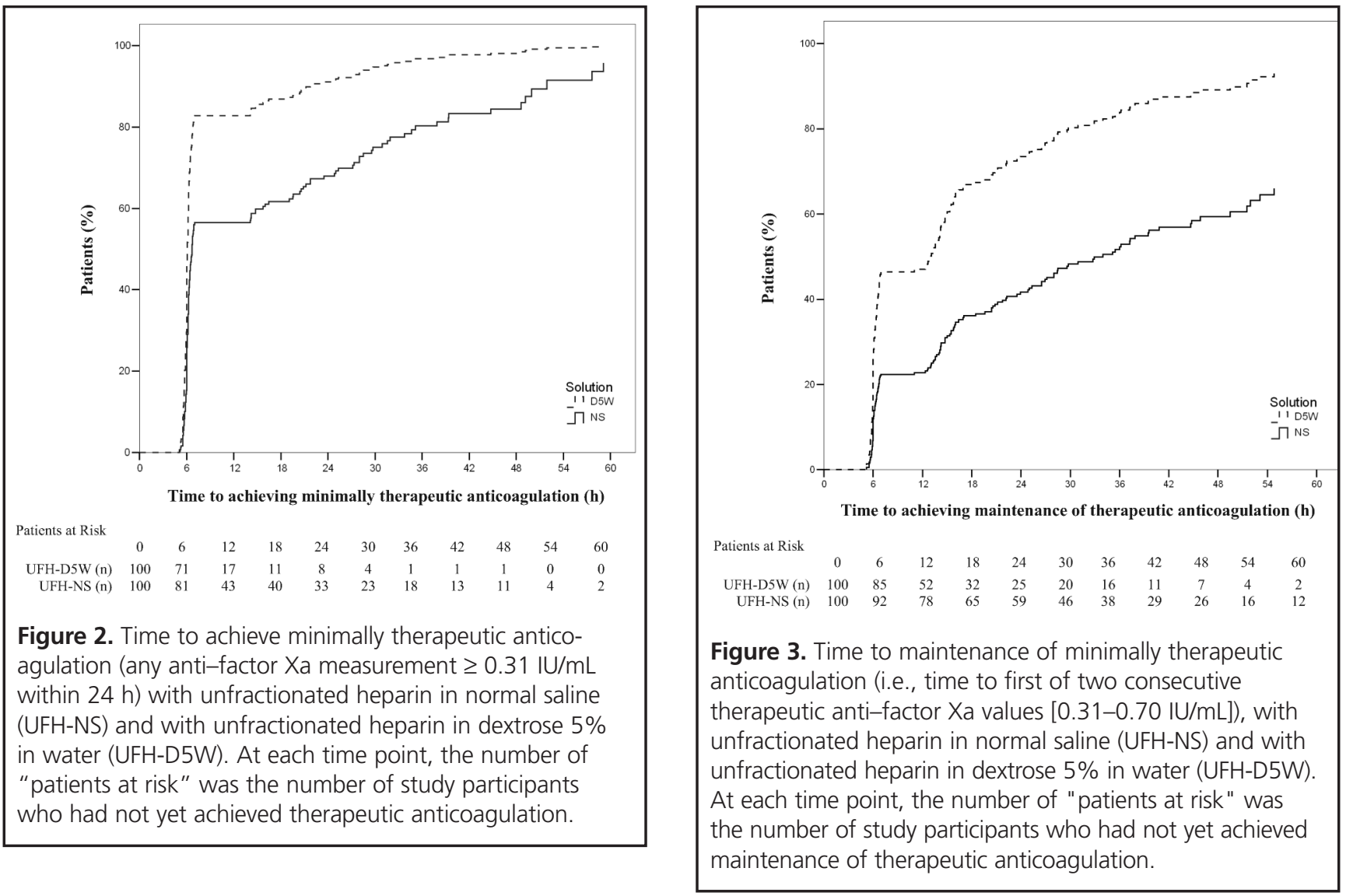

Table 2. Distribution of Anti-Factor Xa Values at First, Second, and Third Measurements after Initiation of UFH Infusion

\begin{tabular}{|c|c|c|c|c|c|c|}
\hline \multirow[b]{2}{*}{ Measurement* } & \multicolumn{2}{|c|}{$\begin{array}{c}\text { Subtherapeutic Anti-Xa } \\
(\leq 0.30 \mathrm{IU} / \mathrm{mL})\end{array}$} & \multicolumn{2}{|c|}{$\begin{array}{l}\text { Therapeutic Anti-Xa } \\
(0.31-0.70 \mathrm{IU} / \mathrm{mL})\end{array}$} & \multicolumn{2}{|c|}{$\begin{array}{l}\text { Supratherapeutic Anti-Xa } \\
(\geq 0.71 \mathrm{IU} / \mathrm{mL})\end{array}$} \\
\hline & No. (\%) & $p$ value & No. (\%) & $p$ value & No. (\%) & $p$ value \\
\hline First (after 6 h) & & $<0.001$ & & 0.007 & & 0.38 \\
\hline UFH-D5W $(n=100)$ & $17(17)$ & & $60(60)$ & & $23(23)$ & \\
\hline UFH-NS $(n=100)$ & $43(43)$ & & $40(40)$ & & $17(17)$ & \\
\hline Second & & $<0.001$ & & 0.001 & & $0.038 \dagger$ \\
\hline UFH-D5W $(n=100)$ & $23(23)$ & & $71(71)$ & & $6(6)$ & \\
\hline UFH-NS $(n=100)$ & $61(61)$ & & 39 (39) & & $0(0)$ & \\
\hline Third & & 0.004 & & 0.01 & & 0.72 \\
\hline UFH-D5W $(n=91)$ & $25(27)$ & & $61(67)$ & & $5(5)$ & \\
\hline UFH-NS $(n=88)$ & $43(49)$ & & $42(48)$ & & $3(3)$ & \\
\hline
\end{tabular}

UFH-D5W = heparin sodium 100 units/mL in dextrose $5 \%$ in water, UFH-NS = heparin sodium

100 units $/ \mathrm{mL}$ in $0.9 \%$ sodium chloride.

*After mandatory measurement of anti-factor Xa at $6 \mathrm{~h}$ after initiation of infusion, the timing of

further measurements of anti-Xa for each patient was dependent on the result of the previous

measurement, according to the nomogram.

†Yates correction.

higher frequency of infusion rate adjustments and anti-Xa measurements noted with infusion of UFH-NS than with UFH-D5W would be expected to result in increased nursing workload and laboratory costs.

A mechanism explaining the differences in the effectiveness of UFH-NS and UFH-D5W has not been established.
Given that the available data have consistently demonstrated that UFH-NS is more stable than UFH-D5W, ${ }^{6-9}$ the differences in effectiveness observed between the study groups seem unlikely to be related to solution stability (although stability testing was not performed). Furthermore, adsorption of heparin to materials appears unlikely to have contributed to the 
results, as the infusion-related materials (e.g., IV bags, tubing) were the same for both groups. Nonspecific binding patterns and unpredictable pharmacokinetic and pharmacodynamic properties of UFH necessitate frequent monitoring, and the anti-Xa heparin assay is a proven reliable indicator of anticoagulation that is well established in clinical practice. ${ }^{13-15}$ Although the possibility that the substituted product (i.e., UFH-NS) interfered with the anti-Xa assay is worthy of consideration, the possibility that minimal amounts of essentially physiologic solutions of normal saline or $5 \%$ dextrose could affect the accuracy of this highly specific assay is questionable. Possible contributing factors that may warrant additional investigation include changes in $\mathrm{pH}$ or dissociation effects of UFH in different solutions, which have previously been shown to vary widely. ${ }^{6-9}$ Additional investigations comparing the anti-Xa activity of heparin in different solutions may help to elucidate whether in vivo mechanisms such as complex protein binding may be involved.

Differences in methods of preparing the UFH solutions may have affected the anti-Xa results, especially for the initial measurements. The preparation of UFH-NS solutions in the study centre's pharmacy involves adding $25 \mathrm{~mL}$ of UFH 1000 units $/ \mathrm{mL}$ to a premixed $250-\mathrm{mL}$ bag of NS, which is stated by its manufacturer to contain an overfill volume of approximately $10 \%$. This would result in an approximate concentration of UFH-NS as low as 83 units $/ \mathrm{mL}$, whereas manufactured UFHD5W solutions contain 100 units $/ \mathrm{mL}$. This decrease in potency of the UFH-NS solution, by up to $17 \%$, may have confounded the anti-Xa results detected at the first measurement. However, this potential difference in concentration does not explain the persistent differences observed over time, as the UFH infusion rates were continuously titrated upward in patients with subtherapeutic anti-Xa levels. If overestimation of the concentration of heparin in UFH-NS explained the differences observed over the treatment period, the anticoagulation curves in both Figures 2 and 3 would be expected to converge. In fact, the Kaplan-Meier curves describing the time to maintenance of therapeutic anticoagulation (Figure 3) remained parallel over the entire treatment period. The curves showing the time to achievement of therapeutic anticoagulation also remained distinct over most of the treatment period, although they did approach convergence at approximately $60 \mathrm{~h}$, which may have been due to the continuous upward titration of heparin infusions in the UFHNS group in response to subtherapeutic anti-Xa results. Although human error in the preparation of the substituted UFH-NS is possible, it is an unlikely explanation for these results, as the solutions were consistently prepared by trained personnel at one sterile manufacturing site, and the number of patients receiving UFH-NS who experienced delays in achieving and maintaining therapeutic anti-Xa levels appeared relatively consistent over the period of data collection.
Exploratory subgroup analyses comparing anti-Xa results according to treatment site or over time within the UFH-NS substitution phase were not conducted because of the small sample size.

An additional limitation of this study was the fact that the substitution of UFH-NS for UFH-D5W because of vendor back order was precipitated by changes that were implemented to reduce the risk of heparin contamination and to standardize the potency of North American USP heparin units with the international reference unit issued by the World Health Organization. These changes in the reference standard were anticipated to result in a decrease of up to $10 \%$ in the potency of each unit of USP heparin relative to heparin products manufactured before October 1, 2009. UFH products with the new potency became available around December 2009, and UFH products of both the old and new potencies were distributed to hospitals simultaneously during this transition period (estimated at up to 2 years). No dosing changes were recommended by regulatory authorities in Canada or the United States, although clinicians were advised to continue to closely monitor patients' coagulation parameters. ${ }^{45}$ Although these potency changes may also have confounded initial anti-Xa measurements, the effects would be expected to dissipate with infusion rate adjustments over the duration of treatment and are unlikely to explain the magnitude of the differences in effectiveness observed in this study. Also, in response to the USP standardization of heparin, a new standard curve for partial thromboplastin time (from which heparin anti-Xa assays are determined) was generated at the study centre. However, the simultaneous availability of heparin preparations of both the old and new potencies may have led to discrepancies with reported anti-Xa results (although these were likely minor). It was not possible to determine retrospectively the potency of the heparin preparations administered to individual patients who received UFH-NS. Finally, the scope of this study was limited in that it was not designed to detect differences in patient outcomes such as bleeding events, myocardial reinfarction, or death. Further laboratory testing and prospective studies may help to elucidate the true magnitude of the differences observed in this retrospective study.

In the event of a future back order of commercially available UFH-D5W solutions or in the event of compelling glucose intolerance, the cautious use of UFH-NS is advised. Patients receiving UFH-NS should be closely monitored, and if a significant delay in the achievement or maintenance of effective anticoagulation is observed, substitution with UFHD5W or alternative anticoagulants may be preferred.

\section{CONCLUSIONS}

UFH-NS was inferior to UFH-D5W for achieving and maintaining therapeutic anticoagulation in patients with 
non-ST-elevation acute coronary syndrome. Until further analyses of UFH solutions are completed, UFH-NS should be used with caution, and patients should be monitored closely to ensure timely achievement and maintenance of therapeutic anticoagulation. Alternatively, UFH-D5W or alternative anticoagulants may be preferred when rapid and reliable anticoagulation is required.

\section{References}

1. Jneid H, Anderson JL, Wright RS, Adams CD, Bridges CR, Casey DE Jr, et al. $2012 \mathrm{ACCF} / \mathrm{AHA}$ focused update of the guideline for the management of patients with unstable angina/non-ST-elevation myocardial infarction(updating the 2007 guideline and replacing the 2011 focused update): a report of the American College of Cardiology Foundation/American Heart Association Task Force on Practice Guidelines. J Am Coll Cardiol. 2012;60(7):645-81.

2. Oler A, Whooley MA, Oler J, Grady D. Adding heparin to aspirin reduces the incidence of myocardial infarction and death in patients with unstable angina: a meta-analysis. JAMA. 1996;276(10):811-5.

3. Theroux P, Ouimet H, McCans J, Latour JG, Joly P, Lévy G, et al. Aspirin, heparin, or both to treat acute unstable angina. $N$ Engl J Med. 1988; 319(17):1105-11.

4. Notice to hospitals: Health Canada issued important safety information on unfractionated heparin. Ottawa (ON): Health Canada; 2009 Nov 25 [cited 2013 May 10]. Available from: www.hc-sc.gc.ca/dhp-mps/alt_formats/ pdf/medeff/advisories-avis/prof/2009/heparin_2_nth-aah-eng.pdf

5. FDA drug safety communication: update: follow up to the public health alert about changes to the heparin sodium USP monograph. Rockville (MD): US Food and Drug Administration; 2010 Apr 7 [cited 2013 May 10]. Available from: www.fda.gov/Drugs/DrugSafety/PostmarketDrugSafetyInformationfor PatientsandProviders/ucm207506.htm

6. Anderson W, Harthill JE. The anticoagulant activity of heparins in dextrose solutions. J Pharm Pharmacol. 1982;34(2):90-6.

7. Goodall KT, Chooi CC, Gallus AS. Heparin stability: effects of diluent, heparin activity, container, and pH. J Clin Pathol. 1980;33(12):1206-11.

8. Mitchell JF, Barger RC, Cantwell L. Heparin stability in 5\% dextrose and 0.9\% sodium chloride solutions. Am J Hosp Pharm. 1976;33(12):540-2.

9. Wright A, Hecker J. Long term stability of heparin in dextrose-saline intravenous fluids. Int J Pharm Pract. 1995;3(4):253-5.

10. Top 10 drugs reported as causing harm through medication error. ISMP Can Saf Bull. 2006;6(1):1-2. Available from: www.ismp-canada.org/download/ safetyBulletins/ISMPCSB2006-01Top10.pdf

11. Cruickshank MK, Levine MN, Hirsh J, Roberts R, Siguenza M. A standard heparin nomogram for the management of heparin theapy. Arch Intern Med. 1991;151(2):333-7.

12. Giudice MG, Perreault MM, Rodger MA, Tierney M, Turek M. Validation of an unfractionated heparin nomogram using an anti-factor Xa chromogenic assay. J Inf Pharmacother. 2001;4:100-9.
13. Rosenberg AF, Zumberg M, Taylor L, LeClaire A, Harris N. The use of anti-Xa assay to monitor intravenous unfractionated heparin therapy. J Pharm Pract. 2010;23(3):210-6.

14. Rosborough TK. Monitoring unfractionated heparin therapy with antifactor $\mathrm{Xa}$ activity results in fewer monitoring tests and dosage changes than monitoring with the activated partial thromboplastin time. Pharmacotherapy. 1999;19(6):760-6.

15. Smith ML, Wheeler KE. Weight-based heparin protocol using antifactor Xa monitoring. Am J Health Syst Pharm. 2010;67(5):371-4.

Amanda C Jacques, BSCPharm, ACPR, is a Pharmacist with The Ottawa Hospital, General Campus, Ottawa, Ontario.

Colleen Lougheed, BScPhm, ACPR, was, at the time of this study, a Pharmacist with The Ottawa Hospital, General Campus, Ottawa, Ontario. She is now with London Health Sciences Centre, University Hospital, London, Ontario.

Erika MacDonald, BScPharm, ACPR, is a Pharmacist with The Ottawa Hospital, General Campus, Ottawa, Ontario.

Alan Karovitch, MD, FRCPC, MEd, is Head and Chair of the Division of General Internal Medicine, Departments of Medicine and of Obstetrics and Gynecology, as well as a staff physician, The Ottawa Hospital and University of Ottawa, General Campus, Ottawa, Ontario.

Pierre Giguère, BPharm, MSc, is a Clinical Pharmacy Specialist, The Ottawa Hospital and Ottawa Hospital Research Institute, General Campus, Ottawa, Ontario.

\section{Address correspondence to:}

Amanda $C$ Jacques

The Ottawa Hospital, General Campus

501 Smyth Road

Ottawa ON K1H 8L6

e-mail: ajacques@toh.on.ca

Competing interests: Amanda Jacques received reimbursement from Roche to attend an educational conference in 2013. Erika MacDonald received payment from Boehringer-Ingelheim for 2 presentations to pharmacists about general management of atrial fibrillation and anticoagulation. Pierre Giguère received payments from Bristol-Myers Squibb, Gilead, Merck, and Janssen for lectures and has received grants from Bristol-Myers Squibb for investigator-sponsored trials (other than the study reported here). No competing interests declared by Colleen Lougheed or Alan Karovitch. 